\title{
Heart Failure after Aortic Valve Replacement for Aortic Valve Stenosis: Possible Mechanisms
}

\author{
Wilhelm P. Mistiaen*
}

Dept. of Healthcare Sciences; Artesis-Plantijn University College of Antwerp, Antwerp, Belgium

\begin{abstract}
Introduction: Aortic valve stenosis imposes a pressure overload on the left ventricle. Congestive heart failure is one of the complications which can appear, even years after the operation. The main questions are: why do patients still develop heart failure? Which types of congestive heart failure can be expected? Which factors related to it are known?

Methods: A literature search was performed with the terms "aortic valve disease/replacement AND heart failure". Some secondary references derived from their reference list were also included. The study design of the selected papers differed considerably. Therefore, the analysis is descriptive and concerns factors which can be related to congestive heart failure. Furthermore, surrogate outcomes are ejection fraction, hypertrophy, long axis ventricular function, torsion, left atrial indices, pressures in the left sided heart and in the pulmonary circulation as well as a number of other echocardiographic parameters.

Results: It has become clear that decrease in ejection fraction, which is the most commonly used parameter, occurs late in the course of aortic valve stenosis, when damage to the left ventricle has already been inflicted. Several more sensitive imaging and Doppler parameters can demonstrate these changes earlier in the course of aortic valve stenosis. This damage proves to be irreversible, at least in part. This might explain the appearance of heart failure after aortic valve replacement. Although this type of heart failure is mostly "diastolic" in nature, a continuum with the systolic type probably exists, at least in patients with aortic valve stenosis.

Conclusions: Damage to the left ventricle in patients with aortic valve stenosis can go unnoticed if ejection fraction is used as sole determinant of left ventricular function, for the timing of operation. Detection of more subtle changes, even in asymptomatic patients with severe aortic valve stenosis should lead to early replacement. This might result in less postoperative heart failure.
\end{abstract}

Keywords: Calcified aortic valve stenosis, Aortic valve replacement, Diastolic heart failure, Systolic heart failure.

\section{INTRODUCTION}

Calcified aortic valve stenosis (AS) has a highly lethal course once it becomes symptomatic. Aortic valve replacement (AVR) is the only way to improve survival rate and to diminish symptoms such as exercise intolerance and dyspnea [1]. These symptoms are related to congestive heart failure $(\mathrm{CHF})$. The improvement of survival rates and relief of symptoms of CHF in patients with AS are the main goals of AVR. However, CHF is not always prevented or cured by AVR. Postoperative CHF is also the most common reason for readmission after AVR [2], as well as the most common cause of death in patients with a high degree of myocardial fibrosis [3]. Postoperative CHF can be defined as symptoms of NYHA class III/IV during at least 4 weeks or as death in which CHF plays a primary or contributive role or as need for mitral surgery for functional mitral regurgitation (FMR), with exclusion of prosthesis valve endocarditis or thrombosis [4, 5]. An alternative definition consist of dyspnea, fatigue on ordinary effort, and a resting PCW of at least $15 \mathrm{mmHg}$. When if LVEF is above $50 \%, \mathrm{CHF}$

"Address correspondence to this author at the Dept. of Healthcare Sciences; Artesis-Plantijn University College of Antwerp, J De Boeckstr, 10, 2170 Antwerp, Belgium; Tel: 32364182 41; Fax: 32364182 71;

E-mail: wilhelm.mistiaen@uantwerpen.be is considered as "diastolic" in nature [6]. This entity needs to be distinguished from systolic CHF [7]. Improvement of left ventricular (LV) ejection fraction (LVEF) after AVR translates into improved survival [8]. Nevertheless, mortality [9] and CHF [10] remain important events after AVR. This indicates that changes of the left sided heart and especially of the LV induced by AS are not fully reversible after AVR. It is reasonable to suppose that these persistent alterations also reflect the effect of AS on preoperative LV function (LVF) and structure. The factors leading to these irreversible changes need review. Although the LVEF is widely used as parameter [11], it is only a crude measure to estimate the systolic LVF. A normal LVEF is considered above $45 \%$ [12] or $50 \%$ [13], but this has low discriminatory power to detect diastolic changes in LV function [7]. In our own series, median LVEF was over $60 \%$, even in octogenarian patients. Nevertheless, postoperative $\mathrm{CHF}$ has also been recorded in these series [9, 10]. The myocardium is not compressible. Hence, the subendocardial layers of a hypertrophied LV are pushed more inwardly, thereby squeezing the content in a larger degree. Therefore, one could expect that an LVEF of $50 \%$ already indicates a decrease in systolic LVF. This has its importance: myocardial dysfunction starts early in the course of AS and can 
remain subclinical for some time, while LVEF still remains above $50 \%$. Hence, early irreversible damage to the LV needs detection by more sensitive methods.

\section{METHODS}

For this purpose, a literature search was performed with the search terms "aortic valve disease AND heart failure" or "aortic valve replacement AND heart failure". This resulted twice in a series of over 1,600 manuscripts. Adding the term "left ventr" in both resulted still in over 700 papers. The most relevant papers, which were included, dealt with the long-term effect on the changes of the heart induced by AS. Since mortality of unoperated AS is high on short term, postoperative studies with focus on LV parameters have been included, in order to obtain mid and longterm effects of AVR. By comparing series over a long time-span, the effect of improved operative techniques and postoperative care have not been included in this manuscript, although these improvements may interfere with the effect of patient-related factors on the outcome after AVR [14]. Furthermore, papers concerning non-ventricular factors with an effect on postoperative $\mathrm{CHF}$ such as conduction defects, atrial fibrillation, coronary artery disease [10] and valveprosthesis-patient-mismatch [15], have not been included. The latter factor is somehow artificial, since the occurrence of mismatch has an effect in patients with an already decreased LVEF and much less in patients with normal LVF. In order to clarify these ventricular-related factors, some surrogates for the classical LVEF or clinically overt CHF have been scrutinized. These include the refined echocardiographic and catheter-based parameters.

\section{RESULTS}

The effect of AS can be found on the entire left sided heart. Parameters which could serve as marker for damage to the LV are found at several levels, including 1) the level of the LV, 2) directly related to this, the movements of the mitral valve, the trans-mitral flow, 3) the level of the left atrium (LA), and 4) the level of the pulmonary venous circulation (Table 1).Several surrogate Doppler and imaging derived terms have been used to describe the outcome of AVR in patients with AS. These are alphabetically listed in Table 2. These factors can also be used for the timing of AVR in (seemingly) asymptomatic patients.

\section{The Morphological Changes at the Level of the LV Include Hypertrophy and Fibrosis.}

Left ventricular hypertrophy (LVH) has been recognized as a repercussion of AS on the LV $[16,17]$. LVH can be estimated by echocardiographic measuring the septal and posterior wall thickness using validated formula [6, 18-20] or by cardiac MRI [21]. The ratio between LV mass index and LV end-diastolic volume index increases in patients with AS [22]. Concentric and eccentric $\mathrm{LVH}$ can be distinguished and be related to diastolic resp. systolic CHF [7]. LVH compensates for overload on the LV, imposed by AS and helps

Table 1: Summary of the Effects of AS at the Different Levels of the Circulation

\begin{tabular}{|c|l|}
\hline At Ventricular and Mitral Level & \\
\hline \hline morphological & LVH, even after correction for LVEF and CAD \\
& Fibrosis, irrespective of CAD and reduced LVEF \\
& LV strain on ECG in asymptomatic patients \\
\hline functional & Stiffness / increase in LVEDP / diastolic dysfunction / impaired LV filling \\
& Decreased long axis LV function or low longitudinal strain [especially if LVEF is below 40\%] \\
& Circumferential strain \\
& Isovolumetric contraction / relaxation time - Tei index [IRT+ICT/ejection time] \\
& Decrease in LVEF \\
& Torsion-to-shortening ratio TSR ratio \\
& FMR \\
& E, A, E', E/A and E/E' \\
\hline At atrial and pulmonary level & Increase in LA volume, alone or in combination with FMR \\
& Increase LA pressure \\
& PALS, PACS \\
& Atrial arrhythmias / AF \\
& Increase in pulmonary vein pressure, A, S and D waves \\
\hline
\end{tabular}


Table 2: Definition of Surrogate Terms

\begin{tabular}{|c|c|}
\hline Term & Definition \\
\hline A & late trans-mitral diastolic filling, additional parameter for patients with indecisive E/E' [between 8 and 15] for LVEDP \\
\hline $\operatorname{Ar}$ & atrial reversal wave, propagating from the left atrium to the pulmonary veins \\
\hline Deceleration time & onset of lengthening to onset of diastasis \\
\hline $\mathrm{dP} / \mathrm{dt}$ & rate of rise of pressure in the LV \\
\hline $\mathrm{E}$ & trans-mitral inflow, early diastolic mitral amplitudes, early filling velocity, E wave deceleration time \\
\hline$E^{\prime}$ & early mitral annular velocity [septal and lateral] \\
\hline $\mathrm{E} / \mathrm{A}$ & $\begin{array}{l}\text { ratio between early and late LV filling velocity and hence a parameter for diastolic dysfunction; corresponds with } \\
\text { prolongation of total filling time }\end{array}$ \\
\hline $\mathrm{E} / \mathrm{E}^{\prime}$ & $\begin{array}{l}\text { parameter for LV diastolic function, representing LVEDP / LA filling pressure; combines the trans-mitral driving } \\
\text { pressure and myocardial relaxation }\end{array}$ \\
\hline FMR & $\begin{array}{l}\text { regurgitation through the mitral valve, without structural valve disease; a consequence of LVH and LV dilatation with } \\
\text { resulting tethering of chordate tendineae; the effective regurgitating orifice is at least } 10 \mathrm{~mm}^{2}\end{array}$ \\
\hline ICT & isovolumetric contraction time \\
\hline IRT & isovolumetric relaxation time \\
\hline $\begin{array}{l}\text { Longitudinal } \\
\text { dysssynchrony }\end{array}$ & maximum opposing LV wall delay in time-to-peak strain at apical view [long axis, 2 chamber and 4 chamber view] \\
\hline LAVI & left atrial volume index \\
\hline LVEDD & left ventricular end diastolic volume \\
\hline LVEDP & left ventricular end diastolic volume \\
\hline LVEF & [LVEDD - LVESV] / LVEDV where LVEDV $=100 \%$ \\
\hline LVESD & left ventricular end systolic volume \\
\hline LVH & left ventricular hypertrophy LVM>109g/m² [females] $>134 \mathrm{~g} / \mathrm{m}^{2}$ [males] \\
\hline LV-longitudinal strain & ratio of length at contraction and initial length \\
\hline MAPSE & mitral annular plane systolic excursion \\
\hline PACS & peak atrial contraction strain \\
\hline PALS & peak atrial longitudinal strain, at the end of the reservoir phase \\
\hline Peak D & peak diastolic flow velocity in pulmonary veins, represents also diastolic LVF \\
\hline Peak LV-longit. strain & peak negative value on the strain curve during the entire cardiac cycle \\
\hline S & peak systolic mitral annular amplitude \\
\hline S/D & ratio between the systolic and diastolic flow velocity in pulmonary veins, representing diastolic LVF \\
\hline Strain & unit in change of length relative to its original length \\
\hline Strain rate & strain / time \\
\hline Tei-index & {$[\mathrm{ICT}+\mathrm{IRT}] /$ ejection time } \\
\hline Torsion & clockwise rotation of the apical part and counterclockwise rotation of the basal part of the heart \\
\hline $\mathrm{Vp}$ & flow propagating velocity \\
\hline
\end{tabular}

to maintain LVEF and wall stress [6, 19, 23, 24], at least in an initial phase [25]. LVH is the result of hypertrophy of the myocytes [24] and of fibrosis [19, 11]. Concentric LVH is an important reason for diastolic dysfunction. The relaxation slows down and early ventricular filling has reduced. The contribution of the atrial contraction and hence, of the late ventricular filling becomes more important. Even in asymptomatic patients with AS, LVH continues to progress as long as the overload exists. LVH can be considered as maladaptive and not merely as compensatory in patients with AS [6]. LVH can lead to impaired coronary vasodilator reserve, LV dysfunction and symptoms of $\mathrm{CHF}$ [8]. LVH with signs of strain on ECG is associated with an increased risk for CHF [26]. Higher LVM is also associated with lower LVEF and with an increase in 
$\mathrm{CHF}$, independent from the severity of AS. Even more, absence of LVH in patients with critical AS is considered favorable.

Fibrosis can be documented and quantified by cardiac MRI $[8,27,28]$ as well as by biopsy $[3,29]$. Fibrosis is the result of increase in collagen content of the myocardium [29] and starts at the sub-endocardium and affects mainly longitudinal LVF. This contributes to diastolic and systolic dysfunction [8, 11], LV dilatation, [3] and to symptoms of CHF [29]. Although, there is a wide overlap in degree of fibrosis between healthy controls a patients with AS, fibrosis is more present with the latter [28]. This overlap might be due to the wide variation in fibrosis in patients with $A S$ and with a preserved LVEF. The degree of fibrosis does not correlate to the severity of AS, however [29]. Fibrosis can be considered as a maladaptive LV remodeling in AS [24], and is multifocal and widespread. Its presence predicts poor outcome, even after AVR [27]. Matrix metalloproteinase and their tissue inhibitors are involved in the remodeling of the cardiac extracellular matrix during overload conditions. These enzymes are in a delicate balance, which shifts to inhibition of matrix metalloproteinase during pressure overload of the ventricle. Finally, this results in accumulation of collagen [24].

The Functional Changes of the LV Include Stiffness, Pressures, Isometric Contraction I Relaxation Time, Tei-Index, Dp/Dt, Longitudinal LVF, Circumferential Strain, Filling Pressures, Torsion-to-Shortening Ratio and Longitudinal Dissynchrony

Diastolic filling of the LV is the result of the interplay between filling pressures and filling properties. These are stiffness (or the ratio between changes in pressure and changes in volume) and compliance (which is the reverse ratio). These properties are usually referred to as "end-diastolic". Early filling of the LV is driven by suction caused by energy-dependent relaxation. This induces an intra-ventricular pressure gradient between base and apex [30]. Ischemia can decrease the diastolic LV function and slows the intra-ventricular propagation of the pressure wave with a concomitant reduction of apical suction. However, this propagation velocity can misleadingly be normal with increased LV filling pressures and normal LVEF. Stiffness of the LV can be documented in patients with AS and LVH [17]. This parameter can be used as a surrogate for fibrosis and can be derived from echocardiography while documentation of fibrosis requires biopsy or cardiac
MR [24]. Concentric LVH and stiffness are important contributors to increased LV end-diastolic pressure or LVEDP [31] and to a delayed relaxation of the LV [19]. Changes in isoforms of titin contribute to stiffness of the LV wall. Titin is the largest sarcomeric protein and functions as a spring. It limits the range of motion of sarcomeres. The shorter isoform N2B is responsible for a higher degree of stiffness compared to the longer isoform N2BA. In patients with overload to the LV due to AS, the total content of titin does not alter, but the shorter isoform has increased. This increase in stiffness can occur in the early stage of LVH [32].

The $\mathrm{dP} / \mathrm{dt}$ ratio is the rate of pressure rise in the LV and a good index of LV performance. It is sensitive to changes in contractility, but less to changes in preload and not at all to changes in after load. It can be used to assess systolic LVF in patients with poor imaging quality [33]. Determination of LVEDP can confirm the diagnosis of diastolic LV dysfunction as wells as of the presence of $\mathrm{CHF}$ in symptomatic patients with preserved LVEF. LVEDP rises before LA pressure does. This is the consequence of diastolic LV dysfunction [34] and is the first hemodynamic abnormality. LVEDP is related to the pulmonary capillary wedge pressure and LA pressure, which are not the same, however. Rise in LA pressure occurs in a more advanced stage of the disease. The is volumetric contraction time (ICT) increases in patients with AS, but only in severe cases. This points to a slower systolic contraction. A prolonged effort of the LV can present itself as a delayed peak of contraction. Subendocardial ischemia can be a possible mechanism [25]. The isovolumetric relaxation time (IRT) can also be estimated by echocardiography [12]. The Tei-index is the sum of ICR plus ICT divided by ejection time. It analyses global LVF and is rather independent from heart rate, systolic and diastolic blood pressure [33]. It is a sensitive parameter for $\mathrm{CHF}$. Change in any of the three parameters contributes to the change in the Tei-index. This index decreases in patients with AS with diastolic dysfunction but preserved LVEF since IRT shortens and ejection time is prolonged. In contrast, the Tei-index is increased in patients with AS and decreased LVEF, because ICT is prolonged and ejection time has shortened. This index distinguishes between normal and decreased LVF in patients with symptomatic AS, with high sensitivity and specificity [34, 35]. The Tei-index cannot be used in patients with atrial fibrillation, arrhythmias and conduction defects [33], conditions which are not rare in patients with AS. 
Torsion is a shear deformation and is caused by the counterclockwise rotation of the apical part of the LV while the basal part rotates clockwise, from apical point of view. Torsion is due to the spiral arrangement of the myocardial fibers. All fibers experience the same force, but the epicardial fibers have a larger lever arm. Torsion contributes to the systolic thickening of the LV wall and to ejection of blood [36]. Untwisting starts late in the systole and occurs mostly during the RT period on ECG and ends at the mitral opening. Decreased untwisting is related to a decreased diastolic LV function. The torsion-to-shortening ratio (TSR) is consistent during systole. A uniform shortening of cardiac fibers is maintained by the relation between torsion and ejection. A change of TSR indicates differences in trans-mural fiber contractions, caused by subendocardial ischemia in patients with AS. The peak systolic twist and the peak apical rotation of the LV increase proportionally with the severity of AS: subendocardial ischemia results in loss of the inhibiting effect of the subendocardial fibers [36-39]. Stiffening of the valvular plane as well as LVH might result in a decrease in basal rotation, with a compensatory increase in apical rotation, in order to maintain LVEF [37]. Concentric LVH itself also leads to an increased torsion. AS also leads to a delay in relaxation and to a delay in the reverse of the apical twist [36]. Torsion during systole results in coiling and storing of energy in the LV. This energy is released during isovolumetric relaxation and results in a suction and rapid filling of the LV [36]. A change in TSR might be an additional parameter to estimate the stage of AS in patient with still preserved LVEF.

Longitudinal LVF is determined by longitudinally oriented fibers. These are located subendocardially and hence are vulnerable to ischemia, resulting in contractile and relaxation abnormalities $[12,17]$. AS selectively decreases longitudinal LVF and strain $[40,41]$. Longitudinal LVF is not well reflected by LVEF, since the latter remains normal for a longer time $[17,40,42]$. Hence, longitudinal LVF is more sensitive in detecting myocardial damage [11]. Longitudinal systolic LVF also correlates with fibrosis [43]. Long axis LVF is very sensitive in early documenting myocardial abnormalities in patients with AS [43]. In order to preserve LVEF, circumferential and rotational strain increase as compensation. Increased torsion of the LV during systole might also be helpful herein [11]. Circumferential strainis more affected by aortic valve regurgitation and less by AS, while longitudinal strain is most affected by AS [44]. Although increased circumferential strain compensates for a decreased longitudinal strain to maintain LVEF, in patients with severely decreased LVF, this compensation is lost [39, 40]. Longitudinal dyssynchrony is an important contributing mechanism in the progression of $\mathrm{CHF}$ and of LV remodeling [11]. LVH and fibrosis can lead to distorted electrical activation and hence impaired LV filling [45]. Non-uniformity in the damage of cardiomyocytes may lead to dyssynchrony and nonuniform regional LV dysfunction. Longitudinal dyssynchrony has an adverse effect on diastolic and systolic LVF as well as on LA and right ventricular function. Radial and circumferential strain seems to be less affected. Time course indicates that with increasing severity of AS, longitudinal LV dysfunction leads to and predicts dyssynchrony [11].

\section{The Changes at the Mitral Level Includes Mitral Annular Displacement and the Related Parameters as Well as Functional Mitral Regurgitation}

During systole, the LV shortens in the long axis, whereby the mitral annulus moves towards the apex. The annulus returns during diastole in an early and a late phase in patients with sinus rhythm: the early phase reflects the rate of myocardial relaxation; the late phase is the result of the atrial contraction [12, 46]. Mitral annular displacement reflects global long axis LVF $[33,43]$ and can be used as surrogate for LV longitudinal strain [47]. The velocity of the mitral annulus displacement does not depend on pressure gradients, as is the case for blood flows [46]. This velocity reflects the rate of change in LV long-axis dimension and LV volume, which on its turn is related to global LV function and to myocardial relaxation [33, 48]. In a diseased LV, relaxation can become nonuniform, which lessens the correlation between mitral annular velocity and global LV relaxation [46]. Velocities and amplitudes of the mitral annulus seem to be more sensitive for systolic LVF compared to LVEF. This mitral annular plane systolic excursion (MAPSE) has several components: longitudinal, rotational and translational. It decreases in patients with AS [17]. Some cut-off values have been determined. If it is below 7 or $8 \mathrm{~mm}$, it indicates that LVEF is below $50 \%$, a value of $10 \mathrm{~mm}$ or more is linked to a LVEF of at least $55 \%$. It is doubtful, however if this relation is valid in LVH and hence, in most patients with AS. Moreover, MAPSE cannot detect small myocardial abnormalities [33]. Mitral DT or deceleration time of early LV filling velocity is an important parameter for stiffness of the LV. DT can be measured from the mitral annular excursion [12] and represents diastolic LV function. A 
shortened DT during mitral inflow indicates a restrictive filling [8].

The $E$ wave represents the early diastolic peak of trans-mitral flow $[22,46]$ and is determined by the pressure gradient between the LA and the LV. The latter is affected by LVF $[14,49]$. Early diastolic filling increases in patients with AS [17, 18]. However, atrial dysfunction has to be taken into account [46]. The A wave represents late trans-mitral diastolic filling and is determined by the pressure gradient between LV and LA during late diastole. It increases in patients with AS and decreased relaxation of the LV $[17,2,46]$. In this condition, the mitral valve opens later. The emptying of the LA is delayed. At the start of its contraction, the LA is still relatively filled and the $A$ wave increases. The $A$ wave is affected by the compliance of the LV and the contractility of LA. The A wave can be valuable in patients whose E/E' value is located between 8 and 15 and in whom the LV filling pressure is difficult to predict [46]. The E/A ratio between early and late trans-mitral LV filling velocity $[18,50]$ serves as a parameter of diastolic dysfunction and decreases in patients with AS [17]. A decreased deceleration time or decreased E/A is specific for abnormal LV relaxation but not for changes of filling pressure. The latter also depends on the delay of the relaxation. When the $L V$ relaxation worsens, the LV compliance decreases further. The LA pressure increases, which "overwhelms" the relaxation of the LV. When this occurs, the IRT shortens and E/A increases. It should be noted that with normal LVEF, mitral velocities correlate poorly with hemodynamics. Furthermore, velocities during early LV filling can misleadingly be normal in normal LV volumes but elevated LVEDP. One should be aware that with variable extent of $L V$ relaxation, the pressure gradient between the LA and the LV varies for similar LA pressure. When the LV becomes stiffer, the mitral DT shortens: the filling of the LV decelerates more rapidly if the LA pressure remains constant [51, 52].

The early diastolic mitral annular motion E', is related to recoil and relaxation of the LV and is independent from preload. It serves as indicator for diastolic dysfunction [14]: E' reduces when LV relaxation is impaired, [48], such as in patients with AS $[8,17,22,53]$. E' is measured at the septal and the lateral side and corrects for the influence of myocardial relaxation on the trans-mitral flow E. Mitral annular calcification, which can be observed in patients with AS, is a confounding factor for E'. Moreover, age has also an effect. Combining the influence of the transmitral driving pressure with myocardial relaxation by the ratio $E / E$ ' is a better parameter [46] to estimate diastolic dysfunction [14] or LV filling pressure $[22,48,53,54]$. E/E' is increased in patients with AS [17], at rest and during exercise, compared to healthy controls [22]. A value of 8 or less predicts normal mean LV diastolic pressure, while a value of 15 points to an increased mean diastolic LV pressure [46].

Functional mitral regurgitation (FMR) is rather common in patients with AS [55]. It is the consequence of tethering of the chordate tendineae during dilatation of the LV or of LVH. FMR can be graded from absent, mild, moderate to severe [5] and is associated with larger ventricles and with CHF. Patients with FMR have a tendency for more co-morbid conditions [55]. The close anatomical and physiological relationship, the socalled aorto-mitral coupling could add to FMR in patients with AS [47]. There is a fibrous continuity between the mitral and the aortic valve [56]. Through this structure, AS might affect the dynamics of the mitral annulus. During LV systole, the normal mitral annulus contracts and pulls at the fibrous region, enlarging the aortic annular area. This facilitates systolic ejection. Conversely, during LV diastole, the mitral annular area expands. This improves LV filling. Hence, there is a mutual facilitation of the function of both valves [47]. FMR leads to a reduced torsion and recoil rate [36].

\section{The Changes at the Atrial and Pulmonary Venous Level Include Atrial Sizes and Strain}

The LA acts first, as a reservoir during the ventricular systole, before the opening of the mitral valve, second, as a conduit, between the opening of the mitral valve and the start of the atrial contraction, and third, as a pump, contributing to the LV enddiastolic volume. Diastolic dysfunction of the LV leads to remodeling of the LA [7]. Filling pressures reflect Doppler based velocities and LA size reflects cumulative effects. The latter is also a predictor for adverse cardiac events, but this has to be considered in conjunction with the clinical status of the patient [57]. When the relaxation of the LV is impaired, the early diastolic AV gradient as well as the LA conduit volume decreases. In order to maintain LV end-diastolic volume, the pump and reservoir function of the LA have to increase. AS leads to considerable dysfunction, not only of the LV but also of the LA, irrespective of the degree of LVH [17]. The increase in LA pressure is necessary for an adequate filling of the stiffer LV and points to a more advanced stage. This results in an enlargement of the LA [45], a decreased atrial 
contractile function and atrial arrhythmias such as postoperative AF [17,58]. This is not an innocent event $[10,17]$. LA area has a significance in determining LV filling pressure [46]. Increased LA volume index (> $40 \mathrm{ml} / \mathrm{m}^{2}$ ) is associated with LVH and increased LV end-diastolic pressure. LA volume index is of more importance compared to E/E' and provides information "beyond the standard risk factors" [58].

PALS (peak atrial longitudinal strain) and PACS (peak atrial contraction strain) decrease in patients with AS [17]. Predictors for increase in global PALS are change of mean transvalvular gradient and the E/A ratio [17]. LA volume does not correlate well with LA strain. Therefore, other parameters are needed to detect dysfunction of the LA. First, the Frank-Starling mechanism (increase in size leading to an increase in output and maintenance of stroke volume) is also active in the LA, but when this relation is exceeded, the contractile function of the LA decreases. Second, the atrial muscle can be affected by the reflected waves during systole. This mechanical relationship is suggested by the reversal of LA volume after AVR. Hence, there is more needed than LVH and LV dysfunction to explain dyspnea and atrial fibrillation in patients with AS [17]. Early detection of changes in LA size and function in patients with AS can be helpful in the selection of patients for AVR as well as for the timing of the operation [17]. The atrium contributes to the LV filling. In small, hypertrophied and noncompliant ventricles, this contribution becomes very important. Atrial fibrillation, especially with rapid LV response and shortened diastolic time will lead to symptoms in patients with AS [8]. The E/E' ratio and MAPSE do not differ between patients with and without AF [17].

Since there are no valves in the pulmonary veins, the flow waves of the atrium correspond with the pulmonary flow waves $\mathrm{D}, \mathrm{S}$ and $\mathrm{A}$. Therefore, anything that increases LA pressure will decrease the flow through the pulmonary vein and can even reverse this flow. An atrial reverse wave can be the result. Anything that decreases the LA pressure will increase the flow from the pulmonary veins into the LA. The peak $D$ wave represents the peak diastolic flow velocity in the pulmonary veins, and indirectly the diastolic LVF [50]. In patients with an ambiguous $E / E$ ' value between 8 and 15 , a pulmonary venous flow during atrial contraction exceeding the duration of the mitral flow with $30 \mathrm{msec}$. might give an indication of LV filling pressures [46]. The $S$ wave represents the systolic flow velocity and is influenced by relaxation or compliance of the LA. The S/D is the ratio between the systolic and the diastolic flow velocity in the pulmonary veins and represents diastolic LVF [50]. A combination with pulmonary venous velocity might improve the diagnostic value of the mitral inflow $E$ as representation of LV diastolic function [46]. The A wave corresponds with the atrial contraction. If the LV compliance has reduced, there is a large $A$ wave in the pulmonary veins. However, if the LA fails mechanically, no A wave can be detected in the pulmonary veins.

\section{Effect of AVR on the LA and LV Parameters}

LVH regresses after AVR [6], but this regression is not always complete [22]. The size of the myocytes decreases, the extent of fibrosis does not [27-29]. Factors for persistent LVH are age and large LV end diastolic dimension [19]. Predictors for regression of LVH are baseline LVM, LA volume [39] and the Teiindex [59]. Because of this incomplete regression, exercise induced LV filling pressure [23], longitudinal LV strain and function [17, 39, 40, 42, 43, 60], do not reverse fully. TSR recovers after $\operatorname{AVR}[37,40]$, probably because of reduction of subendocardial ischemia [11]. However, changes in apical rotation do not, or in part, reverse after AVR $[39,40]$. The improvement of E/E' after AVR is matter for debate: some observe a decrease [17] but without a complete normalization [22]. Others state that $E / E$ ' does not improve. This indicates that after AVR, systolic LV function improves, but diastolic LV function does not [14]. For the LA parameter, the same debate exists [17, 28, 61].

\section{CONCLUSION}

AS causes a remodeling of the complete left sided heart and the venous pulmonary circulation. The LV becomes stiff and fibrotic. The filling pressure increases and changes of the LV diastolic function occur. The LA enlarges and can become also dysfunctional. When the LVEF starts to drop, the changes in the LV might already be irreversible, even when the patient is still asymptomatic. A high number of mutually related and partly overlapping imaging and Doppler derived parameters have been developed in order to detect these early subclinical changes. These parameters might be helpful in more accurate timing of AVR and hence, improving postoperative results. The early stages of CHF might be called "diastolic". When in a later stage LVEF drops, CHF could be called "systolic". Although some consider both types of CHF as two separate disorders, it seems reasonable to 
consider, both conditions of a continuum within the framework of AS: during the progress of the valve disease, the diastolic type can evolve into the systolic type. In patients with dyspnea and known AS with still preserved LVEF, increased volumes of LV and of LA, increased LV mass and increased $E / E$ ' or other Doppler derived parameters can establish the diagnosis of diastolic CHF. Changes of these parameters seem only partially reversible by AVR. Early valve replacement, in a stage where these diastolic changes are still limited might improve the postoperative results. This requires an RCT in which the effect of timing of AVR on the postoperative results is studied. There are several limitations in this review: 1) Due to the vast literature, inclusion of all relevant articles is impossible. The most relevant articles have been included, but this handpicking remains somehow arbitrary. 2) The manuscript is limited to physiological principles. Any indication to echocardiographic techniques and challenges as such have been omitted. 3) Age has an effect on diastolic parameters. Since patients with AS are mostly elderly, this age related effect has to be taken into account: only values of patients over 60 years should be used as baseline parameters. 4) Moreover, in these patients, other conditions such as coronary artery disease, atrial fibrillation, mitral annular calcification, and atrioventricular block can have confounding effects on flow waves. 5) The effect of diastolic ventricular dysfunction on the pulmonary arterial pressure has not been included. 6) Finally, some more complicated parameters such as velocity-time integral of several waves have not been included.

\section{REFERENCES}

[1] Carabello BA. Aortic stenosis: a fatal disease with but a single cure. J Am CollCardiol2008; 1(2): 127-128 DOI: 10.1016/j.jCIN.2007.12.004

[2] Viktorsson SA, Ingvarsdottir IL, Hreinsson K, Sigursson MI, Helgadottir S, Arnorsson P, et al. Aortic valve replacement for aortic stenosis in Iceland 2002-2006: long-term complications and survival. Laeknabladid 2011; 97(11): 591)595.

[3] Milano AD, Faggiani G, Dodonov M, Golia G, Tomezzoli A, Bortolotti $U$, et al. prognostic value of myocardial fibrosis in papteints with severe aortic valve stenosis. J ThoracCardiovascSurg 2012; 144(4): 830-837. DOI: 10.1016/j.jtcvs.2011.11.024

[4] Ruel M, Rubens FD, Masters RG, Pipe AL, Bedard P, Hendry $\mathrm{PJ}$, et al. Late incidence and predictors of persistent or recurrent heart failure in patients with aortic prosthetic valves. J ThoracCardiovascSurg 2004; 127: 149-159.

[5] Ruel M, Kapila V, Price J, Kulik A, Burwash IG, Mesana T. Natural History and Predictors of Outcome in Patients With Concomitant Functional Mitral Regurgitation at the Time of Aortic Valve Replacement. Circulation 2006; 114: 1541-I546. DOI: 10.1161/CIRCULATIONAHA.105.000976
Kupari $M$, Turto $H$, Lommi J. Left ventricular hypertrophy in aortic valve stenosis: preventive or promotive of systolic dysfunction and heart failure? Eur Heart J 2005; 26: 17901796. DOI: 10.1093/eurheartj/ehi344

[7] Paulus WJ, Tschöpe C, Sanderson JE, Rusconi C, Flachskamp FA, Marino $P$, et al. How to diagnose diastolic heart failure: a consensus statement on the diagnosis of heart failure with normal left ventricular ejection fraction by the Heart Failure and Echocardiography Associations of the European Society of Cardiology. Eur Heart J 2007; 28: 25392550.

[8] Lindman BR, Bonow RO, Otto CM. Current management of calcific aortic stenosis. Circ Res 2003; 113: 223-237. DOI: 10.116/CIRCRESAHA. 111.300084

[9] Mistiaen W, Van CauwelaertPh, MuylaertPh, WuytsFI, Harrisson F, Bortier $\mathrm{H}$. Risk factors and survival after aortic valve replacement in octogenarians. J Heart Valve Dis. 2004; 13(4): 538-544.

[10] Mistiaen W, Van CauwelaertPh, MuylaertPh, Wuyts F, Bortier $H$. Risk factors for congestive heart failure after aortic valve replacement with a Carpentier-Edwards pericardial prosthesis in the elderly. J. Heart Valve Dis 2005; 14: 774779.

[11] Yamawaki K, Tanaka H, Matsumoto K, Hiraishi M, Miyoshi T, Kaneko A, et al. Impact of Left Ventricular Afterload on Longitudinal Dyssynchrony in Patients With Severe Aortic Stenosis and Preserved Ejection Fraction. Circ J 2012; 76: 744-751.

[12] Yip G, Wang M, Zhang Y, Fung JHW, Ho PY, Sanderson JE. Left ventricular long axis function in diastolic heart failure is reduced in both diastole and systole: time for a redefinition? Heart 2002; 87: 121-125.

[13] Ding WH, Lam YY, Kaya MG, Li W, Chung R, Chung R, et al. Echocardiographic predictors of left ventricular functional recovery following valve replacement surgery for severe aortic stenosis. Int J Cardiol 2008; 128: 178-184.

[14] Shibayama K, Watanabe H, Tabata M, Sasaki S, Fukui T, Umemura $\mathrm{J}$, et al. Impact of Ejection Fraction on Long-Term Outcome After Elective Aortic Valve Replacement in Octogenarians With Aortic Stenosis. Circ J 2012; 76: 17611767.

[15] Ruel M, Al-Faleh H, Kulik A, Chan KL, Mesana TG, Burwash IG. Prosthesis-patient mismatch after aortic valve replacement predominantly affects patients with preexisting left ventricular dysfunction: effect on survival, freedom from heart failure and left ventricular mass regression. J ThoracCardiovascSurg 2006; 131: 1036-1044. DOI: 10.1016/jtcvs.2005.10.028.

[16] Monrad ES, Hess OM, Murakami T, Nonogi H, Corin WJ, Krayenbuhl HP. Time course of regression of left ventricular hypertrophy after aortic valve replacement. Circulation 1988; 77(6): 1345-1355.

[17] Lisi M, Henein MY, Cameli M, Ballo P, Reccia R, Bennati E, et al. Severity of aortic stenosis predicts early post-operative normalization of left atrial size and function detected by myocardial strain. Int J Cardiol 2013; 167: 1450-1455.

[18] Sharp ASP, Tapp RJ, McG Thorn SA, Frances DP, Hughes $A D$, Stanto AV, et al on behalf of the ASCOT investigators. Tissue Doppler E/E' ratio is a powerful predictor of primary cardiac events in a hypertensive population: an ASCOT substudy. Eur heart J 2010; 31: 747-752.

[19] Zybach-Benz RE, Aeschbacher BC, Schwerzmann M. Impact of left ventricular hypertrophy late after aortic valve replacement for aortic stenosis on cardiovascular morbidity and mortality Int J Cardiol 2006; 109: 41-47.

[20] Van Straten AHM, Hamad MAS, van den Broek KC, ter Woorst JFJ, Elenbaas TW, van Dantzig JM. Increased septum wall thickness in patients undergoing aortic valve replacement predicts worse late survival. Ann ThoracSurg 
2012; 94(1): 66-71.

[21] Breitenbach I, Harringer W, Tsui S, Amorim MJ, Herregods $\mathrm{MC}$, Bogaert $\mathrm{J}$, et al. Magnetic resonance imaging versus echocardiography to ascertain the regression og left ventricular hypertrophy after bioprosthetic aortic valve replacement: results of the REST study. J ThoracCardiovascSurg 2012; 144(3): 640-645.

[22] Seo JS, Jang MK, Lee EY, Yun SC, Kim DH, Song JM, et al. Evaluation of Left Ventricular Diastolic Function After Valve Replacement in Aortic Stenosis Using Exercise Doppler Echocardiography. Circ J 2012; 76: 2792-2798.

[23] Monrad ES, Hess OM, Murakami T, Nonogi H, Corin WJ, Kraeyenbuhl HP. Abnormal exercise hemodynamics in patients with normal systolic function late after aortic valve replacement. Circulation 1988; 77(3): 613-612.

[24] Yarbrough WM, Mukherjee R, Ikonomidis JS, Zile MR, Spinale FG. Myocardial remodeling after aortic valve replacement: mechanisms and future prognostic implications. J ThoracCardiovascSurg 2012; 143[3): 656-664. DOI: 10.106/j.jtcvs.2011.04.044

[25] Moreno R, Zomorano J, Almeria C, Pérez-Gonzalez P, Mataix L, Rodrigo JL, et al. Isovolumetric contraction time by pulsed-wave Doppler Tissue Imaging in aortic stenosis. Eur J Echocardiography 2003; 4: 279-285

[26] Greve AM, Boman K, Gohlke-Bärwolf C, Kesaniemi YA, Nienaber C, Ray S, Egstrup K, et al. Clinical implications of electrocardiographic left ventricular strain and hypertrophy in asymptomatic patients with aortic stenosis. The Simvastatin and Ezetimibe in Aortic Stenosis study. Circulation 2012; 125(2): 346-353 DOI: 10.1161/CIRCULATIONAHA.111.049759

[27] Azevedo CF, Nigri M, Higuchi ML, Pomerantzeff PM, Spina GS, Sampaio RO, et al. Prognostic Significance of Myocardial Fibrosis Quantification by Histopathology and Magnetic Resonance Imaging in Patients With Severe Aortic Valve Disease. J Am CollCardiol 2010; 56: 278-287.

[28] Flett AS, Sado DM, Quarta G, Mirabel M, Pellerin D, Herrey AS, et al. Diffuse myocardial fibrosis in sever aortic stenosis: an equilibrium contrast cardiovascular magnetic resonance study. Eur Heart J - Cardiovasc Imaging 2012; 13(10): 819826. DOI: $10.1093 /$ ehjcj/jes 102

[29] Weidemann F, Herrmann S, Störk S, Niemann M, Frantz S, Lange V, et al. Impact of Myocardial Fibrosis in Patients With Symptomatic Severe Aortic Stenosis. Circulation. 2009; 120: 577-584.

[30] Courtois M, Kovacs SJ Jr., Ludbrook PA. Physiologic early diastolic intra-ventricular pressure gradient is lost during acute myocardial ischemia. Circulation 1990; 81: 1688-1696.

[31] Peterson KL, Tsuji J, Johnson A, Di Donna J, LeWinter M. Diastolic left ventricular pressure-volume and stress-strain relations in patients with valvular aortic stenosis and left ventricular hypertrophy. Circulation. 1978; 58: 77-89; doi: 10.1161/01.CIR.58.1.77

[32] Williams L, Howell N, Pagano D, Andreka P, Vertesaliai M, Pecor T, et al. Titinisoform expression in aorticstenosis. Clin Sci 2009; 117(5-6): 237-242. DOI 10.1042/CS20080248

[33] Hu K, Liu D, Niemann M, Herrmann S, Gaudron PD, Ertl G, et al. Methods foe assessment of left ventricular systolic function in technically difficult patients with poor imaging. $J$ Am SocEchocardiogr 2013; 26: 105-113.

[34] Brutsaert D, Sys SU, Gillebert TC. Diastolic failure: pathophysiology and therapeutic implication. J Am CollCardiol 1993; 22: 318-325.

[35] Haque A, Otsuji $Y$, Yoshifuku S, Kumanohoso T, Zhang $H$, Kisanuki A, et al. Effects of valve dysfunction on Doppler Tei index J Am SocEchocardiogar 2002; 15: 877-883.

[36] Young AA, Cowan BR. Evaluation of left ventricular torsion by cardiovascular magnetic resonance. J CardiovascMagn Res 2012; 14: 49 http: //www.jcmr- online.com/content/14/1/49

[37] Sandstede JJW, Johnson T, Harra K, Beer M, Hofmann S, Pabst $\mathrm{T}$, et al. Cardiac systolic rotation and contraction before and after valve replacement for aortic stenosis. A myocardial tagging study using MR imaging. Am J Roentg2002; 178: 953-958. DOI: 10.2214/ajr.178.4.1780953

[38] Van Dalen BM, Tzikas A, Soliman OII, Heuvelman HJ, Vletter WB, ten Cate FJ, et al. Assessment of subendocardial contractile function in aortic stenosis: a study using speckle track echocardiography. Echocardiography - J Cardiovasc ultrasound All Techn. 2013; 30[3): 293-300. DOI 10.1111/echo. 12051

[39] Staron A, Bansal M, Kalakoti P, Nakabo A, Gazior Z, Pysz P, et al. Speckle tracking echocardiography derived 2dimensional myocardial strain predicts left ventricular function and mass regression in aortic stenosis patients undergoing aortic valve replacement. Int $\mathrm{J}$ Cardiovasclmag 2013; 29(4): 797-808. DOI: 10.1007/s10554-012-0160-z.

[40] Carasso S, Cohen O, Mutlak D, Adler Z, Lessick J, Aronson $\mathrm{D}$, et al. Relation of Myocardial Mechanics in Severe Aortic Stenosis to Left Ventricular Ejection Fraction and Response to Aortic Valve Replacement. Am J Cardiol 2011; 107: 10521057.

[41] $\mathrm{Ng} \mathrm{ACT}$, Delgado $\mathrm{V}$, Bertini M, Antoni ML, van Bommel RJ, van Rijnsoever EPM, et al. Alterations in multidirectional myocardial function in patients with aortic stenosis and preserved ejection fraction: a two dimensional speckle tracking analysis. Eur Heart J 2011; 32[12)1542-1550. DOI 10.1093/eurheartj/ehr084

[42] Dahl JS, Videbaek L, Poulsen MK, Rudbaek TY, Pellika PA Moller JE. Global strain in severe aortic valve stenosis relation to clinical outcome after aortic valve replacement. Circulation - Cardiovasclmag 2012; 5(5): 613-620. DOI: 10.1161/CIRCIMAGING.112.973834

[43] Lam YY, Bajraktari G, Lidqvist P, Holmgren A, Mole R, Li W, et al. Prolonged total isovolumic time is related to reduced long-axis functional recovery following valve replacement surgery for severe aortic stenosis. Int J Cardiol 2012; 159: 187-191.

[44] Li CM, Li C, Bai WJ, Zhang XL, Tang H, Qing Z, Li R. Value of three-dimensional speckle-tracking in detecting left ventricular dysfunction in patients with aortic valvular diseases. J Am SocEchocardiogr 2013; 26(11): 1245-1252. DOI 10.1016/j.echo.2013.07.018.

[45] Zhao Y, Owen A, Henein M. Early valve replacement for aortic stenosis irrespective of symptoms of results in better clinical survival: a meta-analysis of the current evidence. Int $\mathrm{J}$ Cardiol 2013; 168: 3560-3563.

[46] Ommen SR, Nishimura RA, Appleton CP, Miller FA, Oh JK, Redfield MM, et al. Clinical utility of Doppler echocardiography and tissue Doppler imaging in the estimation of left ventricular filling pressures: a comparative simultaneous Doppler-catheterization study. Circulation 2000; 102: 1788-1794. DOI: 10.1161/01.CIR.102.15.1788

[47] Tsang W, Veronesi F, Sugeng L, Weinert L, Takeuchu M, Jeevanadam $\mathrm{V}$, et al. Mitral valve dynamics in severe aortic stenosis before and after aortic valve replacement. $\mathrm{J} \mathrm{Am}$ SocEchocardiogr 2013; 26[6): 606-614. DOI: 10.1016/j.echo.2013.03.004

[48] Hillis GS, Moller JE, Pellikka PA, Gersh BJ, Wright RS, Ommen SR, et al. Noninvasive estimation of left ventricular filling pressure $E / e^{\prime}$ is a powerful predictor of survival after acute myocardial infarction. J Am CollCardiol 2004; 43(3): 360-367).

[49] Ding WH, Lam YY, Pepper JR, Kaya MG, Li W, Chung R, ei al. Early and long-term survival after aortic valve replacement in septuagenarians and octogenarians with severe aortic stenosis. Int J Cardiol 2010; 141: 24-31. 
[50] Majak P, Bjornstadt JL, Braathen B, Lunde IG, Husebye T, Christensen G, Tonnessen T. Endothelin-1 in the Human Myocardium and Circulating Plasma: Evaluation before, during and after Correction of Aortic Stenosis with Aortic Valve Replacement Cardiology 2012; 123: 1-10. DOI: $10.1159 / 000339756$

[51] Little WC, Ohno M, Kitzman DW, Thomas JD, ChengCP. Determination of left ventricular chamber stiffness from the time for deceleration of early left ventricular filling. Circulation 1995; 92: 1933-1939.

[52] Ohno M, Cheng CP, Little WC. Mechanism of altered patterns of left ventricular filling during the development of congestive heart failure. Circulation 1994; 89: 2241-2250.

[53] Shah BN. Echocardiography in the era of multimodality cardiovascular imaging. BioMed Res Int 2013. DOI: 10.1155/2013/310483.

[54] Chang SA, Park PW, Sung K, Lee AC, Park SW, Lee YT, et al. Noninvasive estimate of left ventricular filling pressure correlated with early and midterm postoperative cardiovascular events after isolated aortic valve replacement in patients with severe aortic stenosis. J ThoracCardiovascSurg 2010; 140: 1361-1366.

[55] Takeda K, Matsumiya G, Sakaguchi T, Miyagawa S, Yamauchi $Y$, Shudo $Y$, et al. Impact of untreated mild-tomoderate mitral regurgitation at the time of isolated aortic valve replacement on late adverse outcomes. Eur J CardiothoracSurg 2010; 37: 1033-1038.

[56] Mistiaen W. The aortic valve and its root: the Babylonian tower still stands. AO Anatomy (London Publishing) 2013; 1(3): 29.

[57] Abhayaratna WP, Seward JB, Appleton CP, Douglas PS, Oh JK, Tajik AJ et al. Left atrial size: physiologic determinants and clinical application. J Am CollCardiol 2006; 47: 23572363.

[58] Dahl JS, Videbaek L, Andersen LI, Haghfelt T, Moller JE. Noninvasive assessment of filling pressure and left atrial pressure overload in severe aortic valve stenosis: relation to ventricular remodeling and clinical outcome after aortic valve replacement. J ThoracCardiovascSurg 2011; 142: e77-83.

[59] Tao K, Sakata R, Iguro $\mathrm{Y}$, Ueno $\mathrm{T}$, Ueno $\mathrm{M}$, Tanak $\mathrm{Y}$, et al. Abnormal Tei-index predicts poor left ventricular mass regression and survival after AVR in aortic stenosis patients. J Cardiol 2009; 53(2): 240-247. DOI 10.1016/j.jjcc.2008.11014

[60] D’Ascenzi F, Cameli M, ladanza A, Lisi M, Zaca V, Raccia R, et al. Improvement of left ventricular longitudinal systolic function after transcatheter aortic valve implantation: a speckle-tracking prospective study. Int J Cardiovasclmag 2013; 29(5): 1007-1015. DOI: 10.1007/s 10554-012-0175-5.

[61] Spethmann S, Dreger H, Baldenhofer G, Stueer K, Saghabalyan D, Muelle $E$, et al. Short-term effects of transcatheter aortic valve implantation on left atrial mechanics and left ventricular diastolic function. J Am SocEchocardiogr. 2013; 26(1): 64-71. DOI: 10.1016/j.echo.2012.10.002 